\title{
Suitability of various complex hydrides for foaming aluminum alloys
}

\author{
Paul H. Kamm \\ Structure and Properties of Materials, Technical University Berlin, 10623 Berlin, Germany \\ Francisco García-Moreno, ${ }^{\text {a) }}$ Catalina Jiménez, and John Banhart \\ Structure and Properties of Materials, Technical University Berlin, 10623 Berlin, Germany; and Institute of \\ Applied Materials, Helmholtz Centre Berlin, 14109 Berlin, Germany
}

(Received 8 February 2013; accepted 5 April 2013)

\begin{abstract}
Some hydrides that could replace $\mathrm{TiH}_{2}$ as the hitherto most suitable blowing agent for foaming aluminum alloys were investigated. Hydrides taken from the group $\mathrm{MBH}_{4}(\mathrm{M}=\mathrm{Li}, \mathrm{Na}, \mathrm{K})$ and $\mathrm{LiAlH}_{4}$ were selected since these have not been studied in the past although their decomposition characteristics appear to be suitable. Foamable precursors of alloy AlSi8Mg4 were manufactured by pressing blends of metal and blowing agent powders. Powders, precursors and precursor filings were studied by mass spectrometry to obtain the hydrogen desorption profile. Foaming experiments were conducted with simultaneous x-ray radiographic monitoring. Two Li-containing blowing agents were found to perform well and can be considered alternatives to $\mathrm{TiH}_{2}$.
\end{abstract}

\section{INTRODUCTION}

$\mathrm{TiH}_{2}$ is the blowing agent most frequently used to foam aluminum alloys. This applies to the various melt routes and to the powder-based manufacturing route considered here (see Ref. 1 for an overview of manufacturing routes). $\mathrm{TiH}_{2}$ is suitable because it releases hydrogen gas in the melting range of most aluminum alloys, especially when it has been pretreated by oxidation or chemical filming. ${ }^{2-8}$ However, the cost of $\mathrm{TiH}_{2}$ is quite high, adding $\sim 1 \mathrm{EUR}$ to the cost of $1 \mathrm{~kg}$ of foamable precursor $(\sim 25 \%$ of the total cost). As use of metal foam is currently limited by its high production costs any possible savings are crucial. Alternative blowing agents have been proposed and tested. Carbonates are cheap and have been shown to blow and even stabilize $\mathrm{Al}$ foam, ${ }^{9-11}$ but their use in conjunction with the powder route is difficult and the foams obtained are still inferior to those blown with $\mathrm{TiH}_{2}$. Hydrides have the advantage that no oxide remnant is left behind after decomposition, thus avoiding weakening of the metallic matrix. Besides $\mathrm{TiH}_{2}$, other hydrides of a single element have been evaluated experimentally, including $\mathrm{ZrH}_{2}{ }^{12}$ $\mathrm{HfH}_{2}, \mathrm{LiH}, \mathrm{LaH}_{3}, \mathrm{MgH}_{2},{ }^{13}$ and $\mathrm{CaH}_{2},{ }^{14}$ but none of these showed advantage over $\mathrm{TiH}_{2}$. In this study, we include complex hydrides, which contain a metal and boron, namely $\mathrm{MBH}_{4}(\mathrm{M}=\mathrm{Li}, \mathrm{Na}, \mathrm{K})$, and $\mathrm{LiAlH}_{4}$. These hydrides contain a high amount of hydrogen per unit mass of blowing agent, which determines its price. Moreover, as some of these

\footnotetext{
${ }^{a)}$ Address all correspondence to this author. e-mail: garcia-moreno@helmholtz-berlin.de This paper has been selected as an Invited Feature Paper. DOI: $10.1557 / \mathrm{jmr} .2013 .110$
}

hydrides are considered hydrogen storage materials for a future hydrogen economy they are (or will be) inexpensive materials. ${ }^{15-21}$

A comparison of hydrogen concentration for several borohydrides, $\mathrm{TiH}_{2}$ and $\mathrm{LiAlH}_{4}$ is shown in Fig. 1. We may assess the effect of the different blowing agents on foam production by either (i) considering the variation of theoretical foam expansion produced by a fixed mass fraction of blowing agent, e.g., $0.5 \mathrm{wt} \%$ as typically used for $\mathrm{TiH}_{2}$, or (ii) by reducing the amount of the respective blowing agent so as to achieve the same foam expansion as for $\mathrm{TiH}_{2}$. Reducing the blowing agent content has the advantage that the powder blend might be easier to compact, which in turn could have a positive impact on foaming. ${ }^{22}$ Furthermore, it could reduce costs significantly.

The real situation is more difficult than suggested by Fig. 1. Theoretical maximum foam expansions are not reached in practice due to only partial liberation of hydrogen from the blowing agent at a given foaming temperature and after a given time and hydrogen losses occurring during foaming. ${ }^{23-25}$ Calculating the content of each hydride that would provide an amount of gas equal to that liberated by the benchmark blowing agent $\mathrm{TiH}_{2}$ is not possible without knowing the details of gas generation. Therefore, we decided to leave the mass fraction of each of the new hydrides fixed to $0.5 \mathrm{wt} \%$ for this exploratory study. This implies that some of the new hydrides might not be added in optimal quantities. Once the desorption behavior of the hydrides under foaming conditions is known one will be able to compare the hydrides on the basis of equal amounts of released hydrogen gas. 


\section{EXPERIMENTAL}

\section{A. Materials}

For our foaming trials, we selected the AlSi8Mg4 alloy that is used as a metal foam core material for aluminum foam sandwich panels due to its good foamability. ${ }^{26}$ The metallic elemental and alloy AlMg50 (wt\%) powders described in Table I were mixed with one of the blowing agents for $15 \mathrm{~min}$. Uniaxially hot-compacted tablets of $30 \mathrm{~g}$ mass and $36 \mathrm{~mm}$ diameter were prepared under the usual conditions, namely by first cold compacting for $5 \mathrm{~s}$ at $300 \mathrm{MPa}$ pressure and then hot-compacting at $400{ }^{\circ} \mathrm{C}$ for $15 \mathrm{~min}$ at the same pressure. $10 \times 10 \times 4 \mathrm{~mm}^{3}$-large samples were machined from the precursor for foaming.

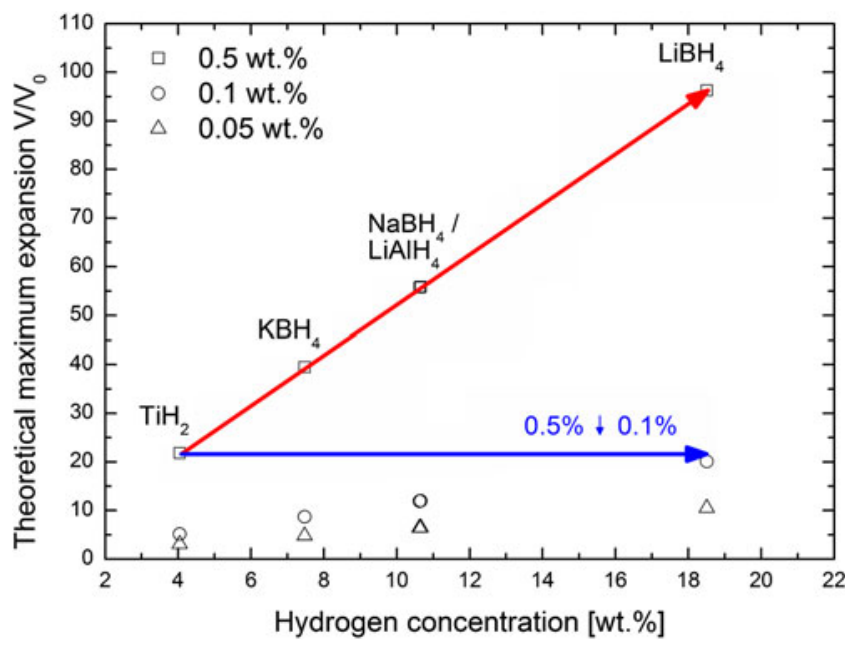

FIG. 1. Comparison of hydrogen concentration and theoretical maximum expansion of foams blown by different blowing agents assuming complete utilization of gas contained in each agent. The red arrow indicates a higher theoretical expansion based on equal mass fractions of blowing agents, and the blue arrow indicates a reduction of the required amount of agent while maintaining a similar expansion.

TABLE I. Metal and blowing agent powders used for the foaming experiments.

\begin{tabular}{llcc}
\hline \hline Powder & \multicolumn{1}{c}{ Supplier } & Purity $(w t \%)$ & $D_{50}(\mu \mathrm{m})$ \\
\hline $\mathrm{Al}$ & Alpoco Ltd. (Sutton Coldfield, UK) & 99.7 & 40 \\
$\mathrm{AlMg} 50$ & $\begin{array}{l}\text { Possehl Erzkontor GmbH } \\
\quad \text { not spec. }\end{array}$ & 30 \\
& $\quad$ (Lübeck, Germany) & & \\
$\mathrm{Si}$ & Alchem Ltd. (Burlington, Canada) & 99.5 & 25 \\
$\mathrm{LiBH}_{4}$ & Sigma Aldrich Chemie GmbH & $\geq 90$ & 70 \\
& $\quad$ (Taufkirchen, Germany) & & \\
$\mathrm{NaBH}_{4}$ & Sigma Aldrich Chemie GmbH & $\geq 96$ & 130 \\
$\mathrm{KBH}_{4}$ & Sigma Aldrich Chemie GmbH & $\geq 98$ & 30 \\
$\mathrm{LiAlH}_{4}$ & Sigma Aldrich Chemie GmbH & 95 & 30 \\
$\mathrm{TiH}_{2}$ & Chemetall GmbH & 98.9 & 15 \\
& $\quad$ (Frankfurt, Germany) & & \\
\hline \hline
\end{tabular}

\section{B. Foaming and x-ray analysis}

To study the evolution of expansion and foam structure, x-ray radioscopy was performed during foaming. The imaging system consists of a tungsten microfocus $\mathrm{x}$-ray source operated at $100 \mathrm{kV}$, and a $2240 \times 2368$ pixel flat panel detector, both from Hamamatsu, Japan. Between these two elements, foaming of samples was performed on a heating plate at a foaming temperature of $700{ }^{\circ} \mathrm{C}$, see also Ref. 27. Image analysis allows for the calculation of expansion profiles. A minimum of 3 samples per analysis were analyzed to assess statistical fluctuations.

\section{Mass spectrometry}

Hydrogen release from blowing agents and foamable precursor materials including filings thereof was studied by mass spectrometry in the thermal analysers Netzsch 209C and 409C (Netzsch Gerätebau GmbH, Selb, Germany) coupled via a capillary and a skimmer, respectively, to a quadrupole mass spectrometer. For characterizing the blowing agents dehydrogenation, $10 \mathrm{mg}$ of powder were heated at $10 \mathrm{~K} / \mathrm{min}$ in an $\mathrm{Ar}$ atmosphere. Compacts of $1 \mathrm{~g}$ and $120 \mathrm{mg}$ of filings prepared from tablets were heated at $40 \mathrm{~K} / \mathrm{min}$ under synthetic air up to $660{ }^{\circ} \mathrm{C}$. Protective gas prevented ignition of $\mathrm{Mg}$ and formation of $\mathrm{MgO}$ that would block both the capillary and the skimmer.

\section{Density and electrical conductivity measurements}

The precursor density provides information on the quality of powder densification. It was measured using Archimedes' buoyancy method and a precision balance CPA225SD from Sartorius AG (Göttingen, Germany). Absolute densities were converted to relative densities by dividing them by the theoretical full density $\rho_{\text {th }}$ of the materials listed in Fig. 2(a).

The electrical conductivity reveals not only the quality of powder compaction (related to the density), but furthermore the degree of metallic bonding between the individual powder particles. To achieve a good conductivity the oxide layer of the powders have to break during the consolidation process as $\mathrm{Al}_{2} \mathrm{O}_{3}$ has a much higher resistivity than Al. This happens mostly due to friction during compaction, which is anisotropic in the case of uniaxial compaction. ${ }^{23}$ The conductivity was measured using the four-point method as described in the literature. ${ }^{28}$ The sample surface was treated with 1000 grit paper to ensure a good and reproducible electrical contact for all the samples.

\section{RESULTS AND DISCUSSION}

\section{A. Density and electrical resistivity}

The electrical conductivity is given as a function of relative density in Fig. 2(a). This way of presenting the data shows that higher relative densities lead to higher conductivities of the compacted powder mixtures. 

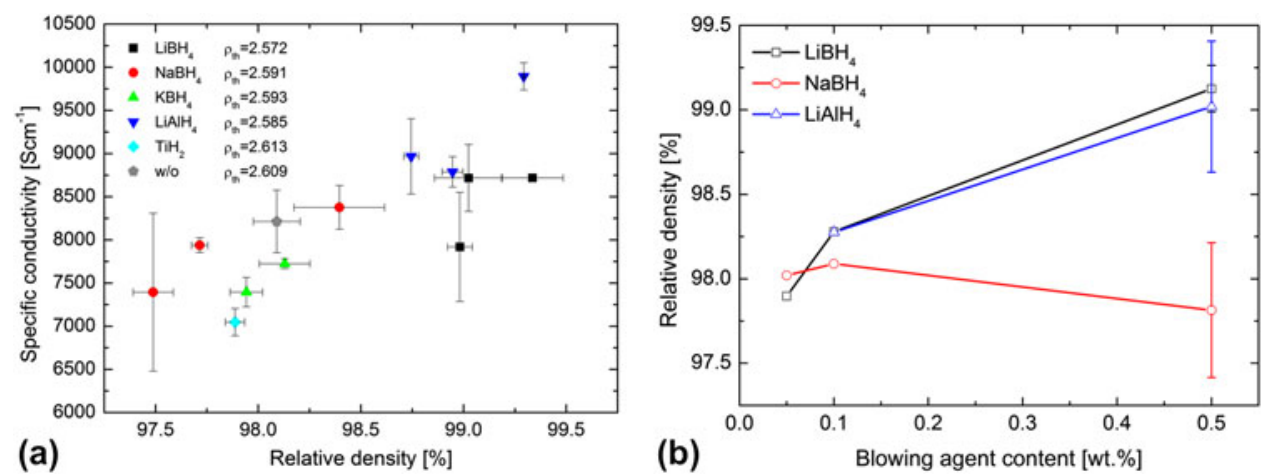

FIG. 2. (a) Specific conductivity versus relative density for AlSi8Mg4 precursors containing 0.5 wt $\%$ blowing agent. Error bars represent each individual sample of a precursor. The calculated full reference densities $\rho_{\text {th }}$ are given. (b) Relative density vs. blowing agent content for Li and Na-containing agents.

Specifically, both the Li-containing blowing agents yield a higher precursor densification. Both densities and conductivities of all these samples exceed the values of the "traditional" precursor containing $\mathrm{TiH}_{2}$. Figure 2(b) gives the relative density as a function of blowing agent content for three of the blowing agents.

Discussion of Fig. 2: In air, aluminum usually forms a tenacious alumina layer that isolates and protects the metal surface. Lithium addition is known to modify these oxide layers and make them less impenetrable due to the reactions it gives rise to. ${ }^{29} \mathrm{Like} \mathrm{Mg}$, Li breaks the closed oxide surfaces and therefore enhances diffusion of metal atoms across metallic contacts and eventually aids sintering. $\mathrm{Li}$ further enhances the effect of $\mathrm{Mg}$ in $\mathrm{Al}-\mathrm{Mg}$ alloys. ${ }^{30,31}$ For this reason it is near at hand to ascribe the better densification of samples containing Li-containing hydrides to the presence of that metal. Figure 2(b) provides further evidence for this picture since the $\mathrm{Li}$ content is correlated with the density of the powder compact for both blowing agents. This does not hold for $\mathrm{NaBH}_{4}$.

$\mathrm{NaBH}_{4}$ is strongly hygroscopic and therefore the inclusion of some water into the powder mixture is hard to avoid during handling. This adverse effect provides an explanation for the lower densification (and conductivity) of the precursor containing that hydride. This negative effect of moisture on $\mathrm{Al}$ powder compaction has been studied previously. ${ }^{24,25}$ However, $\mathrm{KBH}_{4}$ is not hygroscopic and is only marginally better compacted, so that other effects may play a role.

\section{B. Mass spectroscopy}

Hydrogen desorption from $\mathrm{LiBH}_{4}$ powder has three peaks at 90,350 , and $480{ }^{\circ} \mathrm{C}$, see Fig. 3. Filings made from compacted $\mathrm{Al}$ powder containing $\mathrm{LiBH}_{4}$ show two less pronounced shoulders and one peak. If one relates the 3 features in each of the curves to each other, one sees that the gas release in filings is shifted to higher temperatures compared to loose powders. Finally, the single piece of powder compact exhibits the maximum gas release at one

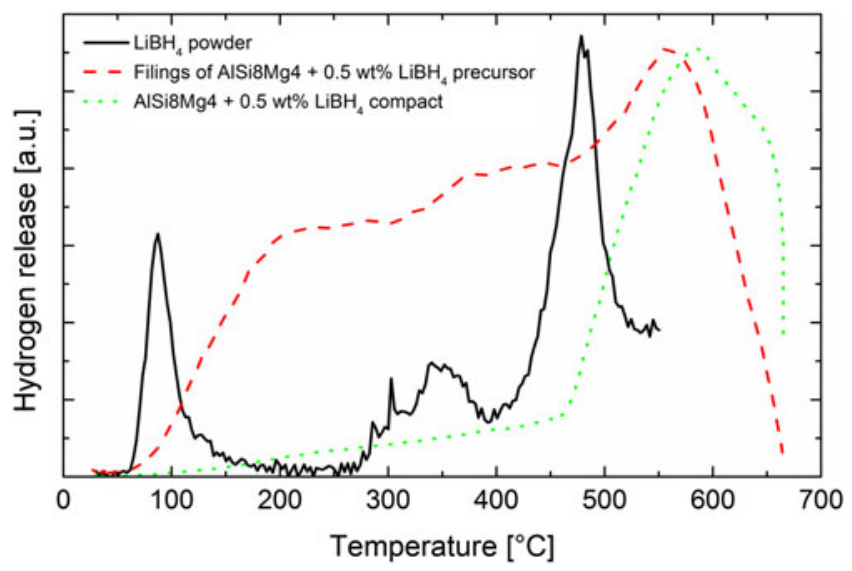

FIG. 3. Hydrogen release from $\mathrm{LiBH}_{4}$ powders, fillings and compacts of AlSi8Mg4 $+0.5 \mathrm{wt} \% \mathrm{LiBH}_{4}$ measured in an Ar atmosphere. Solid: hydride powder (heating rate $10 \mathrm{~K} / \mathrm{min}$ ), dashed line: filings, dotted line: precursor (heating rate is $40 \mathrm{~K} / \mathrm{min}$ in the two latter cases).

single temperature $T=590{ }^{\circ} \mathrm{C}$, which is higher than the other temperatures involved.

Discussion of Fig. 3: The three hydrogen desorption peaks of the powder can be related to the following partial reactions ${ }^{32}$ :

$$
\begin{aligned}
\mathrm{LiBH}_{4} & \rightarrow \mathrm{LiBH}_{4-x}+\frac{1}{2}(x) \mathrm{H}_{2} \\
\mathrm{LiBH}_{4-x} & \rightarrow \mathrm{LiBH}_{2}+\frac{1}{2}(1-x) \mathrm{H}_{2} \\
\mathrm{LiBH}_{2} & \rightarrow \mathrm{LiH}+\mathrm{B}+\frac{1}{2} \mathrm{H}_{2},
\end{aligned}
$$

during which the borohydride releases hydride in three steps and boron is formed. The remaining simple $\mathrm{LiH}$ is stable up to $900{ }^{\circ} \mathrm{C}$, i.e., beyond the temperature range studied here. ${ }^{32}$

The compacted precursor exceeds 99\% density, see Fig. 2. Therefore, the gas cannot escape easily and gives rise to a signal in the spectrometer. Rather, the hydrogen released by the borohydride accumulates in internal voids 
that later grow to bubbles. Insofar, the weak hydrogen release below $500{ }^{\circ} \mathrm{C}$ confirms the quality of the precursor but does not tell us much about the release from the blowing agent.

On the other hand, the hydrogen released from pure powder is transported to the spectrometer quickly, which gives rise to a fast and direct reading. However, it has been observed for $\mathrm{TiH}_{2}$ that loose powder behaves differently from powder that has been mechanically stressed during compaction and is encapsulated in a gas tight Al metallic matrix. Three effects have been discussed: (i) surface oxides on the blowing agent particles can be broken during compaction, which reduces the temperature of gas release. ${ }^{33}$ (ii) the gas released accumulates in the area around the blowing agent particle and builds up a counter pressure of hydrogen which slows down hydrogen release. ${ }^{6}$ (iii) Reactions of the blowing agent with the matrix material or other alloying elements forming e.g., $\mathrm{Al}_{3} \mathrm{Ti}^{5}$ or $\mathrm{TiSi}$ intermetallics might also modify gas release. ${ }^{34}$

The use of filings combines the behavior of powders and compacts since the gas released diffuses to the surface more quickly than in single pieces of powder compacts but still the effect of the metal matrix is present. Therefore, the effects of oxide cracking and gas counter pressure are accounted for, while gas detection is immediate enough to allow us to relate the measured sample temperature to gas release and we use gas desorption measurements on filings to compare the various blowing agent powders.

Figure 4 demonstrates that the various hydrides contained in filings release the gas at very different temperatures. $\mathrm{LiBH}_{4}$ and $\mathrm{NaBH}_{4}$ release the gas to the surroundings at a very early stage, whereas $\mathrm{KBH}_{4}$-containing filings do not. Gas release from both $\mathrm{NaBH}_{4}$ and $\mathrm{KBH}_{4}$ starts to drop above $450{ }^{\circ} \mathrm{C}$ (not counting the small peak at $550{ }^{\circ} \mathrm{C}$ for $\mathrm{NaBH}_{4}$ ). In contrast, the two Li-containing blowing agents, $\mathrm{TiH}_{2}$ and the blowing agent-free compact, show an increasing gas release

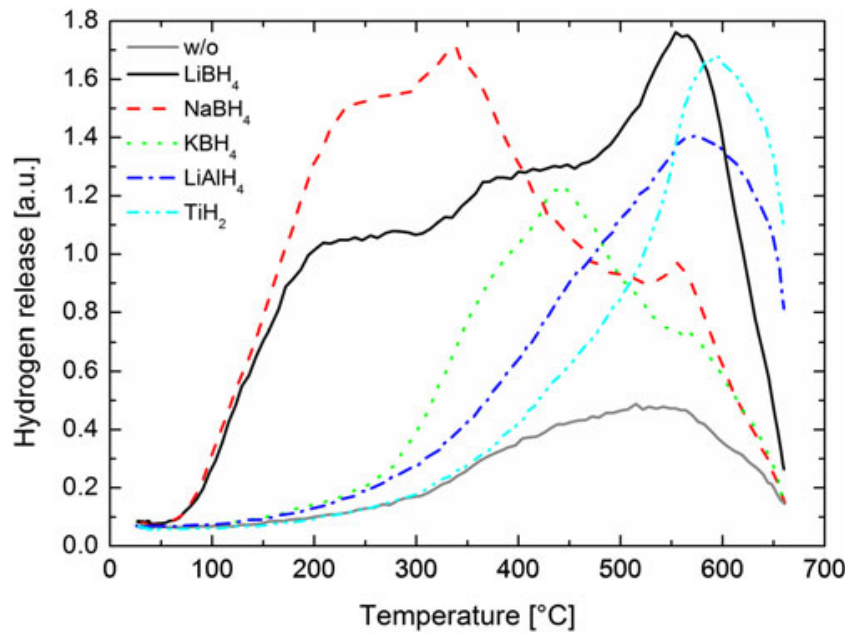

FIG. 4. Hydrogen release from AlSi8Mg4 filings containing $0.5 \mathrm{wt} \%$ of one of the hydrides (or none $=$ w/o). The heating rate was $40 \mathrm{~K} / \mathrm{min}$ and a synthetic air atmosphere was used. rate up to $550-600^{\circ} \mathrm{C}$. Especially, the Li-containing hydrides deliver gas up to the highest temperatures.

Discussion of Fig. 4: Both the early gas release from $\mathrm{NaBH}_{4}$ and its early exhaustion can be related to the lower degree of compaction of that sample. $\mathrm{LiBH}_{4}$ also yields the gas early, probably enhanced by blowing agent particles close to the surface of the filings, but retains some gas up to high temperatures due to its good compaction. This is important for foaming since the gas is needed for the inflation of bubbles and to maintain the pressure in the bubbles after maximum expansion has been reached. $\mathrm{LiAlH}_{4}$ can also hold gas up to high temperatures since it is well compacted as well. This applies to the blowing agent-free sample too, which can also be foamed by pressure manipulation due to the desorbed gases and the good compaction achieved in conjunction with sufficient gas generation in and after the foaming stage. ${ }^{35}$

\section{Expansion}

Foam expansion curves of various materials are given in Fig. 5. The temperature profile applied is shown only for one sample but was very similar in all cases. At least three experiments were carried out for each blowing agent (in some cases more). The statistical scatter of such experiments is nonnegligible and especially maximum expansion shows variations of $\pm 10 \%$, while the general features of the expansion curves are more reproducible. We selected a typical average experiment for Fig. 5 and discuss only features that appear in all the experiments.

Materials containing one of the Li-containing blowing agents consistently start to foam later (or at a higher temperature). Such samples reach about the same maximum expansion. They reach their expansion maximum without the temporary overshooting that is observed for the $\mathrm{K}$ - and Na-based hydrides. Correspondingly, the latter materials

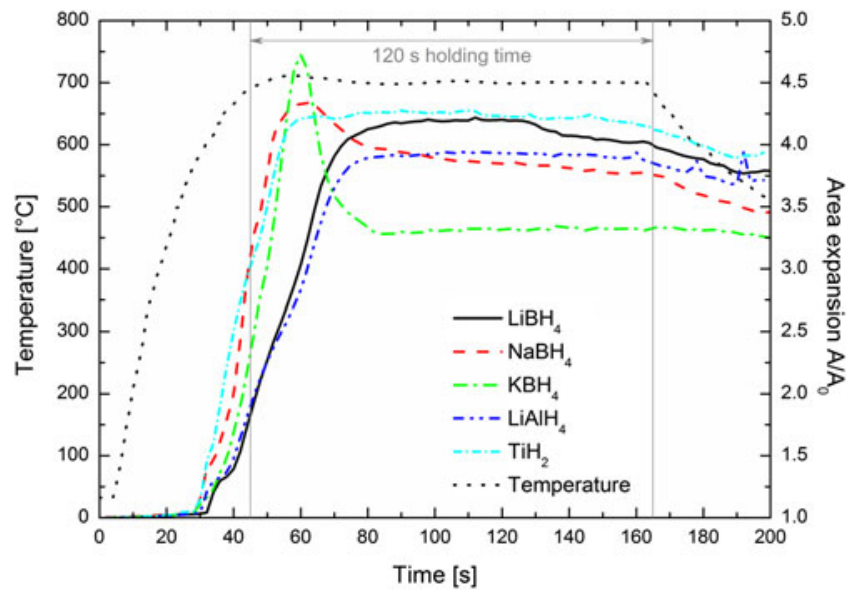

FIG. 5. Area expansion of AlSi8Mg4 foams containing $0.5 \mathrm{wt} \%$ of different blowing agents. The nominal temperature profile was the same for all the samples, which is why only one exemplary temperature curve is given. 
show a visible collapse tendency, whereas the Li-containing hydrides produce foams that remain stable for most of the holding time of $120 \mathrm{~s}$. $\mathrm{LiAlH}_{4}$ gives rise to the most stable foams, which are comparable to the foams blown with $\mathrm{TiH}_{2}$.

Discussion of Fig. 5: All foams show a similar maximum expansion although their blowing agent content is fixed in terms of mass fraction $(0.5 \mathrm{wt} \%)$ and not in terms of gas volume. We do not know how much is released by each blowing agent during foaming but we can assume that the amount varies between the different agents. This demonstrates that the value of maximum expansion does not directly scale with the gas content. It has been reported that an increasing $\mathrm{TiH}_{2}$ content increases the maximum expansion only up to $0.45 \mathrm{wt} \%$ and that contents beyond $0.5 \mathrm{wt} \%$ do not increase foam expansion any more except for a short temporary expansion peak such as the one observed for $\mathrm{NaBH}_{4}$ and $\mathrm{KBH}_{4}$ in Fig. 5, after which the

1

3

34

5
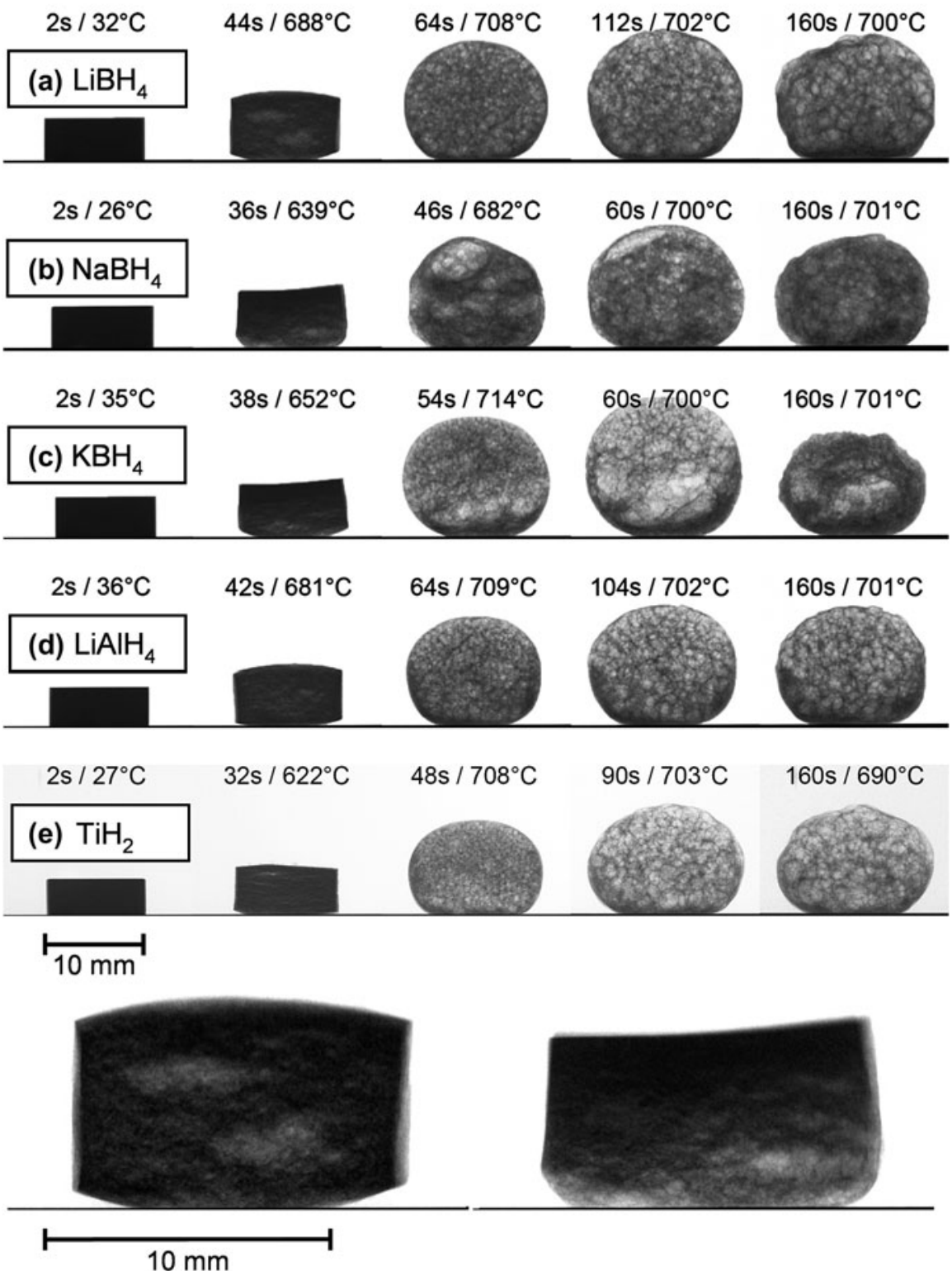

(f) $\mathrm{LiBH}_{4} @ 44 \mathrm{~s}$

(g) $\mathrm{NaBH}_{4} @ 36 \mathrm{~s}$

FIG. 6. X-ray radioscopic image sequence of $\mathrm{AlSi} 8 \mathrm{Mg} 4$ foams in different expansion stages. The blowing agent content was $0.5 \mathrm{wt} \%$ of (a) $\mathrm{LiBH}_{4}$, (b) $\mathrm{NaBH}_{4}$, (c) $\mathrm{KBH}_{4}$, (d) $\mathrm{LiAlH}_{4}$, and (e) $\mathrm{TiH}_{2}$. The expansion stages corresponding to different columns are labeled as: 1: unexpanded precursor, 2: stage of nucleation, 3: stage of growth, 4: stage near maximum expansion and 5: after $120 \mathrm{~s}$ of isothermal holding. Detailed and magnified views of stage 2 of (f) $\mathrm{LiBH}_{4}$ at $44 \mathrm{~s}$ and $(\mathrm{g}) \mathrm{NaBH}_{4}$ at $36 \mathrm{~s}$ are also given. 
foam collapses. ${ }^{36}$ The interpretation is that the ability of a liquid metal film to withstand the stress generated by stretching limits foam expansion rather than the amount of gas available for foaming. According to this interpretation, all the blowing agents investigated in our experiments provide enough (or even too much) hydrogen to achieve the maximum possible expansion level. Even though some of the complex hydrides might provide more gas than $\mathrm{TiH}_{2}$ (where $0.5 \mathrm{wt} \%$ has been found to be an ideal content), they do not give rise to more foam expansion. In future studies, one might want to investigate whether the content of those hydrides can be lowered without sacrificing foam expansion.

The sluggish expansion of the foams blown with the Li-containing agents can be related to the better compaction of the corresponding precursors that have been pressed to a higher density and the counter pressure the hydrogen gas builds up in the melting matrix. Hydrogen released in the liquid state gives rise to growth of round bubbles as opposed to release in the solid state that rather opens and widens cracks and other nonspherical features. The $\mathrm{Li}$ containing blowing agents provide gas up to above $600{ }^{\circ} \mathrm{C}$, see Fig. 4, whereas $\mathrm{NaBH}_{4}$ and $\mathrm{KBH}_{4}$ reach exhaustion and correspondingly the foams collapse partially after no gas is supplied any more. Na could also have an indirect influence via melt properties such as surface tension (i.e., reduced) and solidification contraction (increased) but the exact mechanisms are not known. ${ }^{37}$

\section{Foam structure}

The evolution of the foams blown with different blowing agents as monitored by $\mathrm{x}$-ray radioscopy is shown in Fig. 6. Starting from the initial precursor (1st column) the foams develop small bubbles after about $1 / 2$ min. Here, a difference can be noticed: Li-containing blowing agents or $\mathrm{TiH}_{2}$ lead to a uniform nucleation over the entire sample volume and a convex contour of the early foam, see 2 nd column and Fig. 6(f). $\mathrm{NaBH}_{4}$ and $\mathrm{KBH}_{4}$-containing precursors start foaming in the bottom part only and are concave at the top. As already seen in the expansion curves, see Fig. 5, the Li-containing powders blow the foam slower, reflected by the longer time needed to reach the stage shown in the 2nd column.

The later foaming stages, columns 3-5, reflect the differences seen already in the initial nucleation stage. The foams blown by the Li-containing agents or $\mathrm{TiH}_{2}$ maintain their uniform bubble morphology up to maximum expansion, see column 4, and even until after the isothermal holding stage, however, with some coarsening. $\mathrm{NaBH}_{4}$ and especially $\mathrm{KBH}_{4}$-foamed metal remain nonuniform and prone to drainage as seen from the accumulation of liquid at the bottom of these foams.

Discussion of Fig. 6: In cases where the precursor material foams uniformly and adopts a convex shape, a

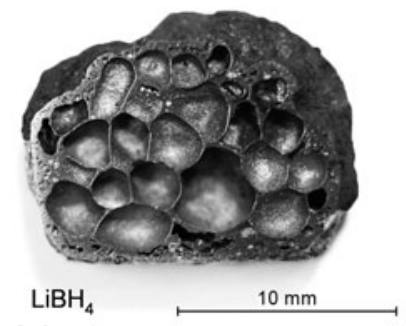

(a)

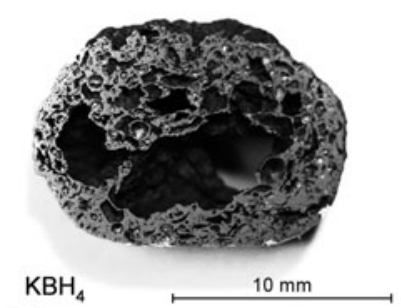

(c)

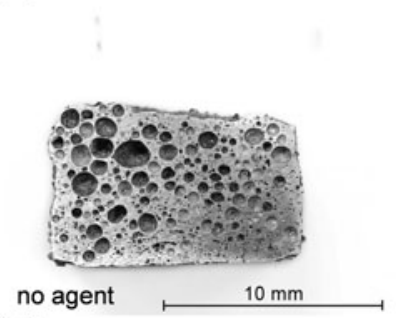

(e)

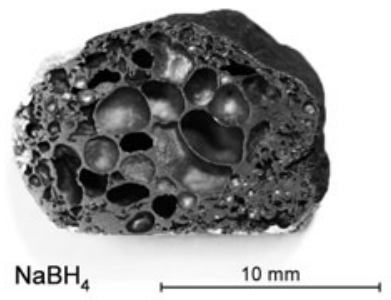

(b)

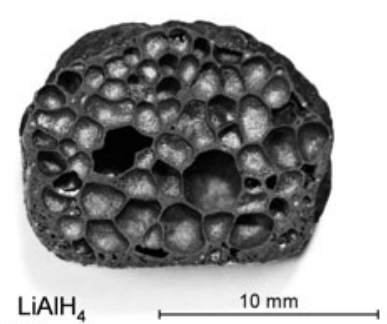

(d)

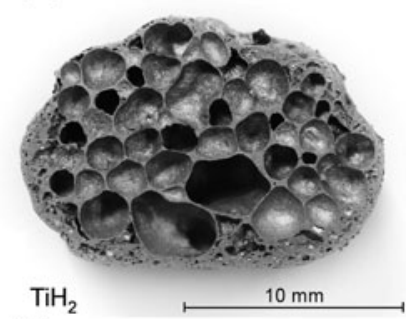

(f)

FIG. 7. Cross-sections showing the pore structure of AlSi8Mg4 foams blown with (a) $\mathrm{LiBH}_{4}$, (b) $\mathrm{NaBH}_{4}$, (c) $\mathrm{KBH}_{4}$, (d) $\mathrm{LiAlH}_{4}$, (e) no agent, and (f) $\mathrm{TiH}_{2}$.

uniform heat transfer into the sample has taken place and has ensured that foaming started everywhere in the sample. In the other cases, the sample has partially lost contact with the substrate at an early stage. Reasons for this could be the insufficient integrity of the samples that were not compacted so well, which enables the formation of cracks and deformation of the sample. Another factor is the lower heat conductivity of the less well compacted samples, which brings heat to the upper part of a foamable tablet at a slower rate.

Postfoaming analysis of the foams solidified after the $\mathrm{x}$-ray experiments, see Fig. 7, confirms the impressions gained by $x$-ray radioscopy. The Li-containing agent and $\mathrm{TiH}_{2}$ produce the most uniform foams. $\mathrm{NaBH}_{4}$ produced only a small region of the good foam structure, while the foam blown with $\mathrm{KBH}_{4}$ has totally collapsed with one large pore remaining in the center surrounded by densified structures. The latter foams also have some open porosity at the outer surface. The best pore structure is obtained for $\mathrm{LiAlH}_{4}$.

Discussion of Fig. 7: The blowing agents containing Na and $\mathrm{K}$ have a negative effect on the films between individual bubbles. Possibly hydrogen can diffuse through the metal films due to fractures, oxide layers or some residual pressing porosity. Gas losses appear largest near the surface, which speaks for the proposed gas loss mechanism by out diffusion. 


\section{SUMMARY}

(i) AlSi8Mg4 foams could be produced with all complex blowing agents investigated: $\mathrm{LiBH}_{4}, \mathrm{NaBH}_{4}, \mathrm{KBH}_{4}$, $\mathrm{LiAlH}_{4}$.

(ii) $\mathrm{LiAlH}_{4}$ followed by $\mathrm{LiBH}_{4}$ produced the foaming results that were closest to the "traditional" blowing agent $\mathrm{TiH}_{2}$.

(iii) Both density and electrical conductivity of the pressed powders were correlated to the expansion height, foam stability and pore quality of the corresponding foams.

(iv) The lithium contained in two of the blowing agents investigated was found to improve compaction. Li has a beneficial effect - similar to $\mathrm{Mg}$ - when aluminum powders are sintered since it breaks the tenacious oxide layer around $\mathrm{Al}$ powder particles that hinders metallic bonding.

(v) $\mathrm{LiAlH}_{4}$ is a suitable blowing agent and is commercially interesting due to its low price. It has a favorable desorption behavior for $\mathrm{Al}$ alloys and leads to foams with a uniform pore structure.

(vi) The content of the new blowing agents needs to be optimized and the compaction conditions could possibly be further adjusted to improve the already very promising first results.

\section{REFERENCES}

1. J. Banhart: Manufacturing routes for metallic foams JOM 52(12), $22(2000)$

2. B. Matijasevic and J. Banhart: Improvement of aluminium foam technology by tailoring of blowing agent. Scr. Mater. 54(4), 503 (2006).

3. V. Gergely and B. Clyne: The FORMGRIP process: Foaming of reinforced metals by gas release in precursors. Adv. Eng. Mater. 2(4), 175 (2000).

4. A.R. Kennedy: The effect of $\mathrm{TiH}_{2}$ heat treatment on gas release and foaming in Al- $\mathrm{TiH}_{2}$ preforms. Scr. Mater. 47(11), 763 (2002).

5. D. Lehmhus and G. Rausch: Tailoring titanium hydride decomposition kinetics by annealing in various atmospheres. Adv. Eng. Mater. 6(5), 313 (2004).

6. B. Matijasevic-Lux, J. Banhart, S. Fiechter, O. Görke, and N. Wanderka: Modification of titanium hydride for improved aluminium foam manufacture. Acta Mater. 54(7), 1887 (2006).

7. C. Jiménez, F. Garcia-Moreno, B. Pfretzschner, M. Klaus, M. Wollgarten, I. Zizak, G. Schumacher, M. Tovar, and J. Banhart: Decomposition of $\mathrm{TiH}_{2}$ studied in situ by synchrotron X-ray and neutron diffraction. Acta Mater. 59(16), 6318 (2011).

8. C. Jiménez, F. Garcia-Moreno, A. Rack, R. Tucoulou, M. Klaus, B. Pfretzschner, T. Rack, P. Cloetens, and J. Banhart: Partial decomposition of $\mathrm{TiH}_{2}$ studied in situ by energy-dispersive diffraction and ex situ by diffraction microtomography of hard X-ray synchrotron radiation. Scr. Mater. 66(10), 757 (2012).

9. T. Nakamura, S.V. Gnyloskurenko, K. Sakamoto, A.V. Byakova, and R. Ishikawa: Development of new foaming agent for metal foam. Mater. Trans. 43(5), 1191 (2002).

10. S.V. Gnyloskurenko, A.V. Byakova, A.I. Sirko, A.O. Dudnyk, Y.V. Milman, and T. Nakamura: Advanced structure and deformation pattern of Al based alloys foamed with calcium carbonate agent, in Porous Metals and Metallic Foams: Metfoam 2007, edited by L.P. Lefebvre, J. Banhart, and D.C. Dunand (DEStech, Montreal, Canada, 2008), p. 399.
11. D.H. Yang, B.Y. Hur, and S.R. Yang: Study on fabrication and foaming mechanism of $\mathrm{Mg}$ foam using $\mathrm{CaCO}_{3}$ as blowing agent. J. Alloys Compd. 461(1-2), 221 (2008).

12. D. Li, J. Li, T. Li, T. Sun, X. Zhang, and G. Yao: Preparation and characterization of aluminum foams with $\mathrm{ZrH}_{2}$ as foaming agent. Trans. Nonferrous Met. Soc. China 21(2), 346 (2011).

13. C. Körner, M. Hirschmann, V. Bräutigam, and R.F. Singer: Endogenous particle stabilization during magnesium integral foam production. Adv. Eng. Mater. 6(6), 385 (2004).

14. D.P. Mondal, M.D. Goel, and S. Das: Effect of strain rate and relative density on compressive deformation behaviour of closed cell aluminum-fly ash composite foam. Mater. Des. 30(4), 1268 (2009).

15. M. Au, W. Spencer, A. Jurgensen, and C. Zeigler: Hydrogen storage properties of modified lithium borohydrides. J. Alloys Compd. 462(1-2), 303 (2008).

16. J.Y. Lee, Y-S. Lee, J-Y. Suh, J-H. Shim, and Y.W. Cho: Metal halide doped metal borohydrides for hydrogen storage: The case of $\mathrm{Ca}\left(\mathrm{BH}_{4}\right)_{2}-\mathrm{CaX}_{2}(\mathrm{X}=\mathrm{F}, \mathrm{Cl})$ mixture. J. Alloys Compd. 506(2), 721 (2010).

17. E. Rönnebro: Development of group II borohydrides as hydrogen storage materials. Curr. Opin. Solid State Mater. Sci. 15(2), 44 (2011).

18. H. Senoh, Z. Siroma, N. Fujiwara, and K. Yasuda: A fundamental study on electrochemical hydrogen generation from borohydrides. J. Power Sources 185(1), 1 (2008).

19. H.W. Li, Y.G. Yan, S. Orimo, A. Zuttel, and C.M. Jensen: Recent progress in metal borohydrides for hydrogen storage. Energies 4(1), 185 (2011).

20. E. Fakioglu, Y. Yurum, and T.N. Veziroglu: A review of hydrogen storage systems based on boron and its compounds. Int. J. Hydrogen Energy 29(13), 1371 (2004).

21. D. Chandra, J.J. Reilly, and R. Chellappa: Metal hydrides for vehicular applications: The state of the art. JOM 58(2), 26 (2006).

22. H.M. Helwig, S. Hiller, F. Garcia-Moreno, and J. Banhart: Influence of compaction conditions on the foamability of AlSi8Mg4 alloy. Metall. Mater. Trans. B 40(5), 755 (2009).

23. M.A. Rodriguez-Perez, E. Solorzano, J.A. De Saja, and F. GarciaMoreno: The time-uncoupled aluminium free-expansion: Intrinsic anisotropy by foaming under conventional conditions, in Porous Metals and Metallic Foams: Metfoam 2007, edited by L.P. Lefebvre, J. Banhart, and D.C. Dunand (DEStech, Montreal, Canada, 2008), p. 75 .

24. C. Jiménez, F. García-Moreno, J. Banhart, and G. Zehl: Effect of relative humidity on pressure-induced foaming (PIF) of aluminiumbased precursors, in Porous Metals and Metallic Foams: Metfoam 2007, edited by L-P. Lefebvre, J. Banhart, and D. Dunand (DEStech, Montréal, Canada, 2008), p. 59.

25. C. Jiménez, F. Garcia-Moreno, M. Mukherjee, O. Goerke, and J. Banhart: Improvement of aluminium foaming by powder consolidation under vacuum. Scr. Mater. 61(5), 552 (2009).

26. H.M. Helwig, F. Garcia-Moreno, and J. Banhart: A study of Mg and $\mathrm{Cu}$ additions on the foaming behaviour of Al-Si alloys. J. Mater. Sci. 46(15), 5227 (2011).

27. F. Garcia-Moreno, M. Fromme, and J. Banhart: Real-time X-ray radioscopy on metallic foams using a compact micro-focus source. Adv. Eng. Mater. 6(6), 416 (2004).

28. I.J. van der Pauw: A method of measuring the resistivity and Hall coefficient on lamellae of arbitrary shape. Philips Tech. Rev. 20, 5 (1958).

29. P.G. Partridge: Oxidation of aluminium lithium alloys in the solid and liquid states. Int. Mater. Rev. 35(1), 37 (1990).

30. A.A. Shirzadi, H. Assadi, and E.R. Wallach: Interface evolution and bond strength when diffusion bonding materials with stable oxide films. Surf. Interface Anal. 31(7), 609 (2001). 
31. A. Ureña, J.M.G. de Salazar, J. Quinones, S. Merino, and J.J. Martin: Diffusion bonding of an aluminium-lithium alloy (AA8090) using aluminium-copper alloy interlayers .1. Microstructure. J. Mater. Sci. 31(3), 807 (1996).

32. A. Züttel, P. Wenger, S. Rentsch, P. Sudan, P. Mauron, and C. Emmenegger: $\mathrm{LiBH}_{4}$ a new hydrogen storage material. J. Power Sources 118(1-2), 1 (2003).

33. C. Jiménez, F. Garcia-Moreno, B. Pfretzschner, P.H. Kamm, T.R. Neu, M. Klaus, C. Genzel, A. Hilger, I. Manke, and J. Banhart: Metal foaming studied in Situ by energy dispersive $\mathrm{X}$-ray diffraction of synchrotron radiation, X-ray radioscopy, and optical expandometry. Adv. Eng. Mater. 15(3), 141 (2013).
34. F. Campana and D. Pilone: Effect of wall microstructure and morphometric parameters on the crush behaviour of $\mathrm{Al}$ alloy foams. Mater. Sci. Eng., A 479(1-2), 58 (2008).

35. F. Garcia-Moreno and J. Banhart: Foaming of blowing agent-free aluminium powder compacts. Colloids Surf., A 309(1-3), 264 (2007).

36. H. Stanzick, I. Duarte, and J. Banhart: Foaming process of aluminum. Materialwiss. Werkstofftech. 31(6), 409 (2000).

37. D. Emadi, J.E. Gruzleski, and J.M. Toguri: The effect of $\mathrm{Na}$ and $\mathrm{Sr}$ modification on surface tension and volumetric shrinkage of A356 alloy and their influence on porosity formation. Metall. Trans. B 24(6), 1055 (1993). 